\section{Methotrexate prolongs TNF inhibitor survival, but only in autoantibody-positive rheumatoid arthritis: a validation study}

With great interest, we read the recently published report by Greenwood et al in which the benefits of coprescription of methotrexate (MTX) with tumour necrosis factor (TNF) inhibitors were investigated in autoantibody-positive and autoantibody-negative rheumatoid arthritis (RA) patients. Greenwood et al found a longer TNF inhibitor survival time when the TNF inhibitor was combined with MTX, which only applied for autoantibody-positive RA patients and thus not for autoantibody-negative RA. ${ }^{1}$ We believe that this finding is of great interest, and relevant, because of its possible implications for treatment with biologics in clinical practice. Because validation is important, we studied this in our cohort.

Within the Erasmus MC, an academic hospital in the Netherlands, we obtained real-world data concerning biological use from the local pharmacy database and patient records. We retrospectively included data from patients with RA who started a TNF inhibitor between 2000 and 2020. In total, 311 patients with RA were included who used etanercept $(\mathrm{n}=142,46 \%)$, adalimumab $(n=90,29 \%)$, certolizumab pegol $(n=59,19 \%)$, infliximab $(n=14$, $5 \%)$ or golimumab $(n=5,2 \%)$ as their first-line TNF inhibitor. The average age at biological start was 46.2 (SD 14.9) years, 257 (82.6\%) were female, average disease duration was 5.1 (SD 5.8) years, and 242 (77.8\%) patients were autoantibody positive (defined as presence of either rheumatoid factor and/or anti-citrillunated protein antibody).

Kaplan-Meier curves stratified for concomitant MTX use and for autoantibody status were plotted, in which other reasons for discontinuation besides ineffectiveness were censored (figure 1). The median TNF inhibitor survival time was significantly longer for autoantibody-positive RA patients with concomitant MTX usage (3.58 years, IQR 1.00-7.01) compared with those without concomitant MTX usage (1.92 years, IQR 0.92-5.3, p=0.021, figure 1A). Furthermore, the HR for the comparison of TNF inhibitor survival in autoantibody-positive RA patients with and without concomitant MTX was 0.74 ( $p=0.042,95 \%$ CI 0.55 to 0.98 ). On the other hand, the median survival time did not differ between autoantibody-negative RA patients with and without concomitant MTX usage (2.58 years in both groups). The HR was 1.22 ( $\mathrm{p}=0.55,95 \%$ CI 0.64 to 2.4 ) (figure $1 \mathrm{~B}$ ).

Hence, we validated the findings of Greenwood et al in an independent set of real-world data. The difference between TNF inhibitor survival time in autoantibody-positive patients with and without MTX usage was smaller in our data, which is common in validation studies. We believe that current findings support the fact that autoantibody-positive and autoantibody-negative RA are two different clinical phenotypes with distinct treatment responses. Recent research showed that treatment strategies that had improved during the last two decennia resulted in more frequent disease activity score (DAS) remission in both autoantibody-positive and autoantibody-negative RA, whereas long-term outcomes such as functional ability, mortality and sustained disease modifying anti-rheumatic drug (DMARD)-free remission improved only in autoantibody-positive RA. The current results on the value of concomitant MTX use for biological survival also point towards differences in treatment response between these two groups. These disconnections, together with differences in risk factors and severity of the disease course, indicate that it is time to formally subdivide RA into type $1 \mathrm{RA}$ (with autoantibodies) and type
2 RA (without autoantibodies) and to promote stratified treatment decisions for these subtypes. ${ }^{2}$

In conclusion, our results support the findings of Greenwood et $a l^{1}$ and underline the importance of handling type 1 and type $2 \mathrm{RA}$ as two different clinical phenotypes with distinct treatment responses and (long-term) outcomes.

Elise van Mulligen $\odot,{ }^{1}$ Annette van der Helm-van Mil $\odot{ }^{1,2}$ Pascal Hendrik Pieter de Jong ${ }^{1}$

${ }^{1}$ Rheumatology, Erasmus MC, Rotterdam, Zuid-Holland, The Netherlands ${ }^{2}$ Rheumatology, Leiden University Medical Center, Leiden, Zuid-Holland, The Netherlands

Correspondence to Elise van Mulligen, Rheumatology, Erasmus MC, Rotterdam 3000 CA, The Netherlands; elise.vanmulligen@erasmusmc.nl

Contributors EvM and PHPdJ were responsible for acquisition of data. EvM and PHPdJ statistically analysed the data. All authors were responsible for interpretation of the data and for drafting, revising and approving the final submitted manuscript.

Funding The authors have not declared a specific grant for this research from any funding agency in the public, commercial or not-for-profit sectors.

Competing interests None declared.

Patient and public involvement Patients and/or the public were not involved in the design, or conduct, or reporting or dissemination plans of this research.

Patient consent for publication Not required.

Ethics approval The protocol was approved by the METC of the Erasmus MC (MEC-2019-0573). No consent was given by participating patients, since this is a retrospective patient record study with anonymous data collection.

Provenance and peer review Not commissioned; internally peer reviewed.

(c) Author(s) (or their employer(s)) 2021. No commercial re-use. See rights and permissions. Published by BMJ.

\section{Check for updates}

To cite van Mulligen E, van der Helm-van Mil A, de Jong PHP. Ann Rheum Dis Epub ahead of print: [please include Day Month Year]. doi:10.1136/ annrheumdis-2020-219499

Received 13 November 2020

Accepted 16 November 2020

Ann Rheum Dis 2021;0:1-2. doi:10.1136/annrheumdis-2020-219499

\section{ORCID iDs}

Elise van Mulligen http://orcid.org/0000-0003-1900-790X

Annette van der Helm-van Mil http://orcid.org/0000-0001-8572-1437

Pascal Hendrik Pieter de Jong http://orcid.org/0000-0001-6628-6222

\section{REFERENCES}

1 Greenwood M, Shipa M, Yeoh SA, et al. Methotrexate reduces withdrawal rates of TNF inhibitors due to ineffectiveness in rheumatoid arthritis but only in patients who are autoantibody positive. Ann Rheum Dis 2020.
A

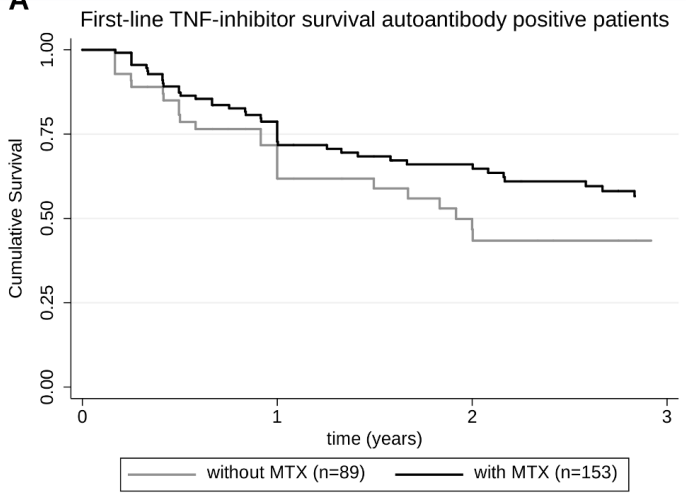

B

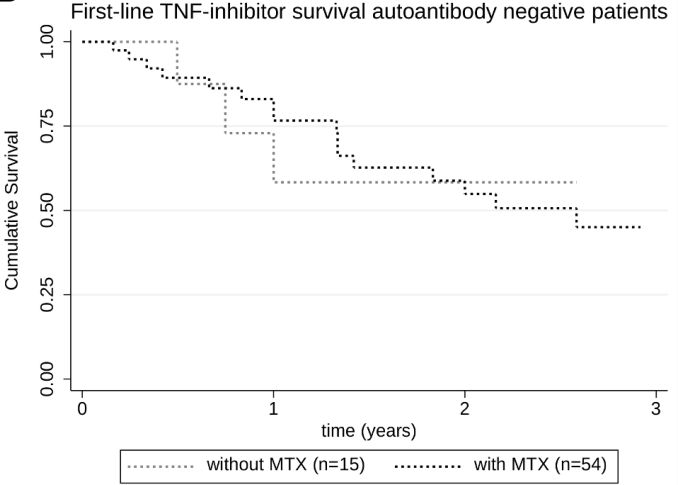

Figure 1 First-line tumour necrosis factor (TNF) inhibitor survival for patients with rheumatoid arthritis stratified for use of concomitant methotrexate (MTX) and for autoantibody status: (A) anti-citrillunated protein antibody (ACPA) and/or rheumatoid factor (RF) positive, and (B) ACPA and RF negative. 
2 Matthijssen XME, Niemantsverdriet E, Huizinga TWJ, et al. Enhanced treatment strategies and distinct disease outcomes among autoantibody-positive and -negative rheumatoid arthritis patients over 25 years: a longitudinal cohort study in the Netherlands. PLoS Med 2020;17:e1003296. 